\title{
BMJ Open Long-term sickness absence of 32 chronic conditions: a Danish register- based longitudinal study with up to 17 years of follow-up
}

\author{
Mette Andersen Nexo, ${ }^{1,2}$ Kathrine Carlsen, ${ }^{3}$ Jacob Pedersen, ${ }^{2}$ \\ Merete Lund Hetland, ${ }^{4,5}$ Torquil Watt, ${ }^{6}$ Sofie Mandrup Hansen, ${ }^{2,7}$ \\ Jakob Bue Bjorner 2,8
}

To cite: Nexo MA, Carlsen $\mathrm{K}$, Pedersen J, et al. Longterm sickness absence of 32 chronic conditions: a Danish register-based longitudinal study with up to 17 years of follow-up. BMJ Open 2018;8:e020874. doi:10.1136/ bmjopen-2017-020874

- Prepublication history and additional material for this paper are available online. To view these file, please visit the journal online (http://dx.doi.org/10. 1136/bmjopen-2017-020874).

Received 5 December 2017 Revised 22 March 2018 Accepted 1 May 2018
Check for updates

For numbered affiliations see end of article.

\section{Correspondence to} Dr. Mette Andersen Nexo; mette.andersen.nexoe@regionh. $\mathrm{dk}$

\section{ABSTRACT}

Objectives Sickness absence has been used as a central indicator of work disability, but has mainly been examined in single diseases, with limited follow-up time. This study identified the risk of long-term sickness absence (LTSA) of 32 chronic disease groups in the first year after diagnosis and the subsequent years.

Setting We identified chronic disease groups prevalent in the work force ( 26 physical and 6 mental conditions) requiring all levels of care (primary, secondary, tertiary), by national registers of diagnoses from all hospital visits and prescribed medicine in Denmark from 1994 to 2011. Participants A general population sample within the working age range (18-59 years) was drawn by Statistics Denmark. Participants not working before and during the follow-up period were excluded. A total of 102746 participants were included.

Primary and secondary outcome measures HRs of transitions from work to LTSA of each of the chronic conditions were estimated in Cox proportional hazards models for repeated events—distinguishing between risk within the first ( $<1$ year) and subsequent years of diagnosis ( $\geq 1$ year) and an HR ratio (HRR): $H R \geq 1$ year divided by $H R<1$ year.

Results Almost all the conditions were associated with significantly increased risks of LTSA over time. The risks were generally more increased in men than in women. Three main patterns of LTSA were identified across diseases: strong decreases of LTSA from the first to subsequent years (eg, stroke in men $<1$ year: $\mathrm{HR}=7.55$, $95 \% \mathrm{Cl} 6.45$ to $8.85 ; \geq 1$ year $\mathrm{HR}=1.43,95 \% \mathrm{Cl} 1.20$ to 1.74; $\mathrm{HRR}=0.23)$. Moderate or small decreases in LTSA (HRR between 0.46 and 0.76). No changes (HRR between 0.92 and 0.95 ) or increases in elevated risks of LTSA over time (HRR between 1.02 and 1.16).

Conclusions The 32 chronic diseases were associated with three different risk patterns of LTSA over time. These patterns implicate different strategies for managing work disability over time.

\section{INTRODUCTION}

The collective burden of mortality and disability from chronic non-communicable
Strengths and limitations of this study

- This study provides a new framework for identifying different risks patterns of long-term sickness absence over time.

- This method allows identification of the short-term and long-term consequences associated with 36 different chronic diseases.

- Additional strengths were validity of diagnosis and the availability of data from all levels of care.

- Among the limitations, we did not evaluate the impact of comorbidity, which is an important risk factor for work disability.

- When comparing the results with other labour market systems, contextual factors need to be considered.

conditions are increasing around the world. ${ }^{12}$ Chronic conditions such as musculoskeletal and psychological disorders, cardiovascular disease, cancers, diabetes and chronic lung diseases are among the most common causes of lifelong disability. ${ }^{2}$ Although the growing number of individuals with chronic conditions threatens work force productivity, ${ }^{3-5}$ research addressing the work-related consequences of the chronic disease burden is scarce, making it difficult to predict and manage implications.

Most high-income countries have an ageing work force. To retain workers, many countries have increased the official retirement age resulting in an even larger proportion of elderly in the work force. ${ }^{67}$ Studies suggest that between $33 \%$ and $50 \%$ of workers have at least one chronic disease increasing to $66 \%$ of workers between 55 and 64 years. ${ }^{5} 8$ This impacts the risks of long-term sickness absence (LTSA), unemployment and early retirement ${ }^{910}$ and threatens the financial 
security, identity and well-being of individuals experiencing chronic disabilities. ${ }^{11}$

LTSA have been used as a central indicator of work disability. ${ }^{12}$ However, few studies have compared risks of LTSA across several chronic conditions. Results from four studies indicated that anxiety and depression were associated with the highest risks of LTSA. ${ }^{13-16}$ The studies showed mixed results regarding the impact of chronic physical conditions on LTSA, probably reflecting the application of different diseases, classifications of diseases, outcome measurements and limited follow-up time.

Studies of inflammatory rheumatic and thyroid diseases found that the first year of diagnosis was associated with higher risks of LTSA than the subsequent years, presumably due to a stabilisation of the condition. ${ }^{17} 18$ A longitudinal study including different chronic diseases is needed to outline the risks of LTSA associated with different chronic conditions over time. The Danish registers of health and social reimbursements provide a unique opportunity to examine work disability associated with various chronic conditions. ${ }^{19}$

This study aimed to identify the risk of LTSA of 32 major chronic disease groups in the first year after diagnosis and the subsequent years.

\section{METHODS}

\section{Population}

The study used a general population sample $(n=137267)$ drawn by Statistics Denmark as a comparison group in a previous study on rheumatoid arthritis. ${ }^{17}$ Participants were of working age (18-59 years) with oversampling of women and participants in the 40-59 age range. We excluded 34521 individuals according to the following criteria: missing values on key variables included in the analyses $(n=22066)$; died prior to study start or were not in the 20-59years interval at any time during follow-up $(\mathrm{n}=1315)$; received disability pension or similar compensation for reduced work ability prior to study start $(n=8113)$; not employed before or during the follow-up period $(n=3027)$. The final sample included 102746 individuals.

\section{Included chronic conditions}

An interdisciplinary group (the authors) with expertise in internal medicine, occupational health and psychiatry, reviewed all the diseases in the WHO's International Classification of Diseases-10th edition (ICD-10) ${ }^{20}$ and included or excluded conditions according to the following criteria:

- We included conditions that were chronic. Physical conditions were defined as chronic if biological processes impacted specific body structures, organs or functions, involving long duration usually requiring life-long treatment or monitoring. ${ }^{21}$ Mental conditions had to be moderate or severe, which implicated intense treatment or monitoring for at least 2 years (eg, bipolar disorder or schizophrenia) or recurrent conditions (eg, episodic depression). We excluded conditions unlikely to be associated with considerable work disability (eg, food allergies).

- The conditions had to be prevalent in the working population (age $20-59$ years).

- We excluded conditions incurring handicaps that made it difficult to enter or re-enter the labour market on normal employment terms. These concerned mainly congenital conditions ('malformation'), conditions diagnosed in childhood or early adulthood (eg, mental retardation) and conditions or injuries that incurred acute death or sudden and permanent exit from the labour market (eg, severe brain injury).

We mostly grouped the chronic conditions according to the organ system involved (eg, diseases of the ear). A few conditions were better suited in another disease group (eg, sarcoidosis was grouped with inflammatory rheumatic diseases). Chronic pain has proven a good predictor of work disability ${ }^{22}$ and was therefore evaluated as an independent disease group in two ways: as a single condition (ie, not registered with any other chronic condition) or as a condition regardless of any other registered comorbid conditions (ie, chronic pain with other possible co-existent chronic conditions). Anxiety and affective disorders often overlap and treatment often implicates the same prescribed medicine. To reduce risk of misclassification we merged anxiety and affective disorders into one disease group. The final list included 26 chronic physical and 6 mental conditions (table 1).

\section{Data sources}

In Denmark, information on health, demography, socioeconomy and social reimbursements are registered in national databases of high quality. ${ }^{19}$ All Danish citizens are assigned a unique personal identification number at birth, administrated by the Central Population Register (CPR), which we used to link data from different registers.

Ethical approval is not required for register studies in Denmark, but we followed standard guidelines as described in the Declaration of Helsinki. The study was registered and approved by the Danish Data Protection Agency, which is required by Danish law (identification number: 2015-41-3828) and allowed access to databases hosted at Statistics Denmark.

\section{Chronic conditions}

The 32 chronic conditions were identified by ICD diagnoses in The Danish National Patient Registry (NPR) ${ }^{23}$ and The Danish Psychiatric Central Research Register (PCRR) ${ }^{24}$ From NPR and PCRR we identified date and every ICD diagnosis registered for the study participants in the study period 1994-2011. Because Danish hospitals must report all inpatient and outpatient visits to NPR and PCRR, the validity is high and risk of misclassification low. ${ }^{23}$

To identify conditions treated in the primary sector by general practitioners, we also used the Danish National Prescription Registry (PRESCRIBE) ${ }^{25}$ PRESCRIBE holds 
Table 1 Overview of ICD-10 codes and ATC codes of included chronic conditions

\section{Chronic disease groups \\ ICD-10 codes \\ ATC codes}

Physical conditions (abbreviated)

Chronic infection (Infec)

A52; B18; B20-24

J05AB04; J05AE; J05AF; J05AG; J05AR; J05A×07

Cancer (Cancer)

C00-C26; C30-C34; C37-41;

C43; C45-58; C60-C85; C88;

C90-97; D45-47

Benign haematologic diseases

including anaemia (Haemo)

D50-D53; D55-58; D66-68;

D69.1; D69.3; D81-84; D89

Diseases of the thyroid gland $\quad$ E00-03; E05-07; E89.0 H03AA01; H03BA02; H03BB01; H03BB02

(Thyroid)

Diabetes (Diabetes)

E10.1-10.9; E11.0-11.9; E12-14

A10A; A10B; A10BA02

Other endocrine diseases and

malnutrition (Endo)

E20-27; E31-32; E34-35; E40- A09AA

46; E50-64

Obesity (Obesity)

E65-66

A08AA03; A08AB01

Neurological diseases (Neuro)

G10-14; G20-26; G30-32; G35- N02C; N03AF; N03AX; N04A; N04B; N07CA03

37; G40-41; G43-46; G60-64;

G70-73; G80; 83; G90-99

Paraplegia and hemiplegia G81-82

(ParaHemi)

Eye diseases (Eyes) H2O-22; H25-28; H30-36; H40;

H06.2; H54; Q11-15

Ear diseases (Ears)

H80; H90-91; H93.1; Q16

Hypertension (Hyperten) I10-I13; I15

C02CA; C07; C08; C09

Ischaemic heart disease and heart I20-25; 142-43; 150

B01AC04; C01AA; C01D;

failure (Heart)

Caridiac arrhythmia and valve

disease (Arrhythm)

I05-09; 134-36; 144-49

C01BC; C01BD

Stroke (Stroke)

$160-69$

Vascular disease (Vascular)

I26-28; 170-74; 177; 179

Chronic pulmonary disease

including asthma (Pulmonary)

E84; J41-47; J60-67; J68.4;

R03; VO3AN01

J70.1; J70.3; J84.1; J84.8-9;

J96
Inflammatory bowel disease
K50-52; K57
A07EA; A07EC02; A07EC03; A07EC04

(Bowel)

Diseases of the liver (Liver) I85; I86.4; 198.2; K70; K71.3-9;

$\mathrm{K} 72-74 ; \mathrm{K} 75.3 ; \mathrm{K} 75.4 ; \mathrm{K} 76 ; \mathrm{K} 86$

Diseases of the skin (Skin) L23-27; L40-1; L43; L45; L93- D05; D07AB; D07AC; D07AD; D07BC; D07CC; D07X; 95; L97

D11AX

Inflammatory rheumatic disease $\quad$ D86; M02-3; M05-10; M14;

(Inflarheum)

M30-32; M34-36; M45-49;

A07EC01; L04AA13; M01CB01; M01CB03; M04AA01; M72.6

M04AB; M04AC

Degenerative rheumatic diseases M15-19; M20-21; M23-25; M40- M01AX

and osteoarthritis (Osteoarthritis) $\quad 43$; M50-51; M54.3-54.5; M75;

M79.7; M84.1; M86.3-86.5;

M87-88; M90.0; M95

Osteoporosis (Osteoporosis) M80-85

Chronic pain (Pain)

G03XC01; H05AA02; H05AA03; M05BA

M01A; N02AA; N02AB; N02AC01; N0AC03; $\mathrm{NOAC0} 4$; N02A $\times 1$; N02A 2 ; N02A $\times 3$; N02A $\times 5$; $\mathrm{N} 02 \mathrm{~A} \times 6$; N02A $\times 52 ; \mathrm{N} 02 \mathrm{~B}$

Chronic pain* (Pain*)

M01A; N02AA; N02AB; N02AC01; NOAC03;

$\mathrm{NOAC0} 4$; N02A $\times 1 ; \mathrm{N0} 2 \mathrm{~A} \times 2 ; \mathrm{N0} 2 \mathrm{~A} \times 3 ; \mathrm{N} 02 \mathrm{~A} \times 5$; $\mathrm{N} 02 \mathrm{~A} \times 6 ; \mathrm{N02A} \times 52 ; \mathrm{N02B}$

Continued 


\begin{tabular}{|c|c|c|}
\hline Chronic disease groups & ICD-10 codes & ATC codes \\
\hline Diseases of the kidney (Kidney) & $\begin{array}{l}\text { E85; N03-5; N07-8; N11; N13.0- } \\
\text { 13.3; N14; N16-19; N25-26; } \\
\text { N30.1; N30.4; N31; N32.1-32.2; } \\
\text { N36.0; N41.1 }\end{array}$ & \\
\hline $\begin{array}{l}\text { Gynaecological diseases } \\
\text { (Gynaecol) }\end{array}$ & N71.1; N73.1; N80 & \\
\hline \multicolumn{3}{|l|}{ Mental conditions (abbreviated) } \\
\hline Dementia (Dementia) & F00-04; F06-7; F09; G30; G31.1 & N06D \\
\hline Substance abuse (Abuse) & $\begin{array}{l}\text { F10.1-2; F10.8-9; F11.1; F11.5; } \\
\text { F11.7-9; F12.1-2; F12.7-9; } \\
\text { F13.1-2; F13.7-9; F14.1-2; } \\
\text { F14.7-9; F15.1-2; F15.7-9; } \\
\text { F16.1-2; F16.7-9; F18.2; F18.6- } \\
\text { 8; F19.1-2; F19.6-7 }\end{array}$ & N07BB01; N07BB04; N07BC01; N07BC02; N07BC51 \\
\hline Schizophrenia (Schizo) & F20-22; F25; F29 & \\
\hline Depression and anxiety (Anxdep) & $\begin{array}{l}\text { F31; F33-34; F40-42; F43.1; } \\
\text { F44-45 }\end{array}$ & N05AN; N05BB; N05BE; N06A \\
\hline Eating disorders (Eating) & F50 & \\
\hline Personality disorders (Personality) & F60-63; F68-69 & \\
\hline
\end{tabular}

${ }^{*}$ Chronic pain classification only if no other chronic comorbidities.

ATC, Anatomic Therapeutic Chemical Classification System; ICD-10, International Classification of Diseases-10th edition.

information on all prescribed medicine in Denmark classified according to the Anatomical Therapeutic Chemical (ATC) coding system. The ATC allows identification of those individuals with chronic conditions that never receive hospital treatment or get admitted to a hospital. The authors, including three medical doctors (MLH, JBB, TW), identified those ATC codes represented drugs as a unique treatment for the specific condition. ATC codes that were used to treat multiple conditions were excluded. Conditions were identified via ATC records only if the prescriptions had been redeemed at least five times during the study period.

Date of diagnosis was obtained from the data source with the earliest date of diagnosis/prescription. From records of ATC codes, dates for redemption and pack size, we were able to identify 20 of the 32 conditions. Table 1 presents all the ICD-10 diagnosis and ATC codes for each disease group.

\section{Long-term sickness absence}

The DREAM register (Danish Register-based Evaluation of Marginalization) covers all residents in Denmark, who have received social transfer payments in any given week since $1991 .{ }^{26}$ During the study period, Danish citizens were able to receive sickness benefits for a maximum of 52 weeks during a period of 2 years if they were unable to work due to illness or disability. In Denmark, from week 1 in 1994 to April 12007 employers were reimbursed by the municipality after a minimum of 2 weeks and after 2 June 2008 after a minimum of 3 weeks, that is, registered in DREAM. Reimbursements are registered in weeks. To reduce risk of misclassification, we classified the participants with LTSA if they received sickness absence benefits for a period of at least 4 consecutive weeks from week 1 in 1994 until week 30 in 2011. Participants re-entered the risk group, when they returned to work after LTSA.

\section{Covariates}

Age and sex were identified via the CPR register and information on education, job type, immigrant and marital status was obtained from the Integrated Database for Labour Market Research, administrated by Statistics Denmark since $1980 .{ }^{2728}$ Calendar year was also included as a covariate.

\section{Statistical analysis}

HRs for the transition from work to LTSA were estimated by Cox proportional hazard models, in separate analyses for each of the 32 chronic conditions. The HR represented the risk of LTSA associated with each of the chronic conditions compared with not having the specific chronic condition (ie, individuals with other comorbidities were not excluded).

We used a multistate model accounting for recurrent episodes of LTSA: work and LTSA were treated as transient states in which the participants could re-enter these states. ${ }^{29}$ Individuals were censored at the end of the study period, or before if they received disability pension, emigrated, died or turned 60 years. Participants who were unemployed, students or on maternity leave were temporarily excluded until they returned to the work state.

All variables were treated as time dependent, except immigrant status which was included as a time independent variable. The underlying time axis for the analysis was age. 
Analyses were performed separately for men and women and for the first and for the subsequent year of diagnosis. Significance level was $\mathrm{p}<0.05$.

The HR values were adjusted for immigrant status, highest attained education, marital status, calendar year and job type.

To provide an overview of the similarities and differences of HR across the conditions, we categorised the reporting of the results according to four levels: extremely elevated ( $H R \geq 4.0$ ), highly elevated $(4.0<\mathrm{HR} \geq 2.5)$, moderately elevated $(2.5<\mathrm{HR} \geq 1.5)$ and mildly elevated $(1.5<\mathrm{HR}>1.1)$.

To be able to evaluate how the HR of each condition changed over time we also estimated an HR ratio (HRR) by dividing HR of the subsequent years with the first year. We categorised according to five levels: extremely decrease (HRR $\leq 0.25)$, strongly decrease (0.25> HRR $\leq 0.40)$, moderately decreased $(0.40>$ HRR $\leq 0.67)$, mildly decreased $(0.67>$ HRR $\leq 0.91)$, no change or increase $(>0.91 \mathrm{HRR}>1.00)$.

All statistical analyses were performed in SAS V.9.2.

\section{Patient and public involvement}

This study was a register study and patients or the public were not involved. However, once the results have been published in a scientific journal the reference and a summary of the main findings of the study will be publicly available on the National Research Center of The Working Environment website.

\section{RESULTS}

The characteristics of the study cohort are presented in table 2. Because of the sampling strategy, women aged 40-59 years constituted the largest group (table 2).

The number and percentage of men and women with different chronic conditions increased from study entry to exit during the 17 years of follow-up (table 3 ).

The number of events (incidence of LTSA), personyears and incidence rates (incidence of LTSA per 1000 person-years) of each of the chronic conditions within the first year of diagnosis and subsequent years are provided in online supplementary web appendix 1.

\section{HR in the first year after diagnosis}

Except for some conditions with few events (chronic infection and thyroid diseases in men; eating disorders, dementia and chronic infection in women), all the other chronic conditions had statistically significant increased risk of LTSA within the first year of diagnosis (table 4 and online supplementary web appendices 1 and 2).

Women and men with cancer or stroke had extremely elevated risk of LTSA (HR 4.75-7.55), as had men with heart disease $(\mathrm{HR}=4.55)$. Women with heart disease had highly elevated risk $(\mathrm{HR}=2.60)$.

For many conditions (inflammatory rheumatic diseases, osteoarthritis, chronic pain, kidney diseases, substance abuse, anxiety and depression and personality disorder), risk of LTSA was highly elevated for both men and women (HR 2.58-3.99). Other conditions had stronger risk for men than for women: benign haematologic diseases, other endocrine diseases and malnutrition, neurological diseases, ischaemic heart disease, cardiac arrhythmia and valve disease, vascular disease and osteoporosis. Accordingly, more conditions were associated with moderately elevated HR within the first year of diagnosis in women than men (table 4).

\section{HR in the subsequent years after diagnosis}

The HR of LTSA was significantly elevated for almost all conditions in the subsequent years of diagnosis (except for women with infection and men with benign haematologic disease or thyroid disease). However, none of the conditions was associated with extremely or highly elevated HR. For both men and women, moderately elevated LTSA risk was seen for: obesity, neurological disease, ischaemic heart disease, pulmonary disease, liver disease, inflammatory rheumatic disease, degenerative rheumatic disease, chronic pain, substance abuse, anxiety and depression. Again, many conditions seemed to carry stronger risk for men than for women: diabetes, eye disease, hypertension, cardiac arrhythmia and valve disease, vascular disease, inflammatory bowel disease, osteoporosis, kidney disease.

\section{Changes in HR between the first and subsequent years}

Table 4 illustrates the overall tendency: the HR of LTSA of each chronic condition was more elevated in the first than in subsequent years.

The decrease in LTSA from the first to the subsequent years was extreme in cancer (for both men and women) and in stroke for men (HR ratios 0.19-0.23; table 4) and strong in paraplegia and hemiplegia and stroke for women and ischaemic heart disease and heart failure for men (HR ratios 0.29-0.37).

In many diseases, the HR of LTSA decreased moderately from the first to the subsequent years (HR ratios 0.46 to 0.66 , table 4 ). A mild decrease in risk of LTSA was observed in both men and women with hypertension, inflammatory bowel disease, liver disease and chronic pain (HR ratios $0.71-0.85$ ), women with thyroid diseases, obesity, diseases of the ear, osteoporosis, depression/ anxiety, diabetes, chronic pulmonary disease and skin diseases (HR ratios 0.70-0.95) and in men with chronic pulmonary disease or skin disease (HR ratio $=0.71-0.76)$.

No change was noted in chronic pulmonary diseases including asthma, diabetes and diseases of the skin for women (HR ratios 0.92-0.95). The risk of LTSA increased slightly in men with obesity (HR ratio $=1.02$ ) or diabetes $($ HR ratio=1.16).

\section{DISCUSSION}

For both men and women, almost all the 32 mental and physical chronic conditions were associated with significantly increased risks of LTSA. The risks remained elevated throughout the study period, but the highest 
Table 2 Overview of number and percentage of demographics variables at start of follow-up (entry) and end of follow-up (exit)

\begin{tabular}{|c|c|c|c|c|}
\hline \multirow[b]{3}{*}{ Variables } & \multicolumn{2}{|c|}{ Women ( $n=75$ 319) } & \multicolumn{2}{|c|}{ Men (n=27 427) } \\
\hline & Entry & Exit & Entry & Exit \\
\hline & $\mathrm{n}(\%)$ & n (\%) & n (\%) & $\mathrm{n}(\%)$ \\
\hline \multicolumn{5}{|l|}{ Age (years) } \\
\hline 20-29 & $14540(19.3)$ & 2165 (2.9) & $3303(12.0)$ & $434(1.6)$ \\
\hline $30-39$ & $16648(22.1)$ & $6851(9.1)$ & $5656(20.6)$ & $1531(5.6)$ \\
\hline $40-49$ & $23064(30.6)$ & $15028(20.0)$ & 9189 (33.5) & $4346(15.8)$ \\
\hline $50-59$ & $21067(28.0)$ & $51275(68.0)$ & $9279(33.7)$ & $21116(77.0)$ \\
\hline \multicolumn{5}{|l|}{ Highest obtained education } \\
\hline Vocational education & $21863(29.0)$ & 24817 (32.9) & 9949 (36.3) & $10564(38.5)$ \\
\hline Primary school/high school & $30930(41.1)$ & $26445(35.1)$ & $9086(33.1)$ & $882(32.2)$ \\
\hline Short or medium long education & $13090(17.4)$ & $16580(22.0)$ & $3897(14.2)$ & $3897(16.6)$ \\
\hline Long education & $2238(3.0)$ & $3731(5.0)$ & $1609(5.9)$ & $1609(7.2)$ \\
\hline Missing & $7189(9.5)$ & $3764(5.0)$ & $2886(10.5)$ & $1505(5.5)$ \\
\hline \multicolumn{5}{|l|}{ Job type } \\
\hline Managers & $2603(3.5)$ & $2044(2.7)$ & 3059 (11.2) & $2426(8.9)$ \\
\hline Highest level of knowledge work & $7190(9.6)$ & 8947 (11.9) & $3523(12.8)$ & $3826(14.0)$ \\
\hline Medium level of knowledge work & $11987(15.8)$ & $15323(20.3)$ & $2959(10.8)$ & $3619(13.2)$ \\
\hline Clerical support work & $13235(17.6)$ & $12045(16.0)$ & $1278(4.7)$ & $1259(5.6)$ \\
\hline Service and sales work & $15094(20.0)$ & $15782(21.0)$ & $1449(5.3)$ & $1785(6.5)$ \\
\hline Agricultural, forestry and fishery & $339(0.5)$ & $295(0.4)$ & $1031(3.8)$ & 907 (3.2) \\
\hline Craft and related trades & $1100(1.5)$ & $1014(1.3)$ & $4911(17.9)$ & $4650(17.0)$ \\
\hline Operators, installation, transport & $3400(4.5)$ & $2980(4.0)$ & $2977(10.7)$ & $3326(12.1)$ \\
\hline Other types of manual labour & 9518 (12.6) & $10483(13.9)$ & $3453(12.6)$ & $4266(15.5)$ \\
\hline Missing & $10853(14.4)$ & $6406(8.5)$ & 2787 (10.2) & $1363(5.0)$ \\
\hline \multicolumn{5}{|l|}{ Marital status } \\
\hline Married/cohabitant & $54030(71.7)$ & $56026(74.4)$ & $19684(71.8)$ & $20646(75.3)$ \\
\hline Single & $16164(21.5)$ & $18349(24.4)$ & $5759(21.0)$ & $6332(23.1)$ \\
\hline Missing & $5156(6.8)$ & $944(1.2)$ & $1984(7.2)$ & $449(1.6)$ \\
\hline \multicolumn{5}{|l|}{ Immigration status } \\
\hline Danish born & $64498(85.6)$ & $64498(85.6)$ & $22416(81.7)$ & $23782(82.6)$ \\
\hline Descendants & $168(0.2)$ & $168(0.2)$ & $50(0.2)$ & $50(0.2)$ \\
\hline Immigrant & $10653(14.2)$ & $10653(14.2)$ & 4959 (18.1) & $4959(18.2)$ \\
\hline \multicolumn{5}{|l|}{ Calendar years } \\
\hline 1994-1999 & 69203 (91.9) & $33098(43.9)$ & 25558 (93.2) & $14370(52.4)$ \\
\hline 2000-2005 & $4412(5.9)$ & 17 (22.6) & $1356(4.9)$ & $5884(21.5)$ \\
\hline 2006-2011 & $1704(2.2)$ & 25236 (33.5) & $513(1.9)$ & $7173(26.1)$ \\
\hline
\end{tabular}

risks of LTSA were seen in the first year after diagnosis (except for men with diabetes or obesity). Overall, the chronic conditions were associated with higher risks of LTSA in men than in women.

By contrast to previous studies, ${ }^{13-16}$ we were able to identify at least three patterns of LTSA characterising the different chronic conditions over time:

1. Conditions with an extreme or strong decrease in HR from the first to subsequent years of diagnosis (HR ratio between 0.23 and 0.29 ; cancer and stroke in men and women, paraplegia and hemiplegia in women and ischaemic heart disease and heart failure in men). These conditions had extremely or highly elevated HR of LTSA in the first year of diagnosis (HR between 4.75 and 7.55 ) presumably reflecting that the conditions involve treatments (eg, surgery, chemotherapy, neurorehabilitation) that required long-term absence from work in the first year. Part of the extreme or strong decrease in LTSA may reflect a permanent exit from the labour market of the sickest individuals 
Table 3 Prevalence of chronic diseases at start of follow-up (entry) and end of follow-up (exit)

\begin{tabular}{|c|c|c|c|c|}
\hline \multirow[b]{3}{*}{ Variables } & \multicolumn{2}{|c|}{ Women $(n=75$ 319) } & \multicolumn{2}{|l|}{$\begin{array}{l}\text { Men } \\
(n=27 \text { 427) }\end{array}$} \\
\hline & Entry & Exit & Entry & Exit \\
\hline & n (\%) & n (\%) & n (\%) & n (\%) \\
\hline \multicolumn{5}{|l|}{ Physical chronic diseases } \\
\hline Chronic infection & $17(0.0)$ & $174(0.2)$ & $<5(0.0)$ & $98(0.4)$ \\
\hline Cancer & $186(0.2)$ & $3439(4.6)$ & $47(0.2)$ & $782(2.9)$ \\
\hline Benign haematologic diseases including anaemia & $47(0.1)$ & $702(0.9)$ & $8(0.0)$ & $125(0.5)$ \\
\hline Diseases of the thyroid gland & $337(0.4)$ & $3776(5)$ & $27(0.1)$ & $252(0.9)$ \\
\hline Diabetes & $148(0.2)$ & $1839(2.4)$ & $111(0.4)$ & $1227(4.5)$ \\
\hline Other endocrine diseases and malnutrition & $51(0.1)$ & $657(0.9)$ & $7(0.0)$ & $117(0.4)$ \\
\hline Obesity & $200(0.3)$ & $3264(4.3)$ & $31(0.1)$ & $405(1.5)$ \\
\hline Neurological diseases & $660(0.9)$ & $6759(9)$ & $98(0.4)$ & $1309(4.8)$ \\
\hline Paraplegia and hemiplegia & $<5(0.0)$ & $25(0.0)$ & $<5(0.0)$ & $12(0.0)$ \\
\hline Eye diseases & $109(0.1)$ & $1797(2.4)$ & $44(0.2)$ & $771(2.8)$ \\
\hline Ear diseases & $126(0.2)$ & $1865(2.5)$ & $64(0.2)$ & $978(3.6)$ \\
\hline Hypertension & $898(1.2)$ & $12152(16.1)$ & $423(1.5)$ & $5217(19.0)$ \\
\hline Ischaemic heart disease and heart failure & $121(0.2)$ & $2083(2.8)$ & $118(0.4)$ & $1831(6.7)$ \\
\hline Cardiac arrhythmia and valve disease & $106(0.1)$ & $1484(2)$ & $52(0.2)$ & $735(2.7)$ \\
\hline Stroke & $46(0.1)$ & $837(1.1)$ & $20(0.1)$ & $435(1.6)$ \\
\hline Vascular disease & $49(0.1)$ & $690(0.9)$ & $19(0.1)$ & $380(1.4)$ \\
\hline Chronic pulmonary disease including asthma & $1209(1.6)$ & $7720(10.2)$ & $264(1)$ & $1899(6.9)$ \\
\hline Inflammatory bowel disease & $121(0.2)$ & $1541(2.0)$ & $40(0.1)$ & $501(1.8)$ \\
\hline Diseases of the liver & $26(0.0)$ & $499(0.7)$ & $17(0.1)$ & $243(0.9)$ \\
\hline Diseases of the skin & $1525(2.0)$ & 9991 (13.3) & $365(1.3)$ & $3073(11.2)$ \\
\hline Inflammatory rheumatic disease & $182(0.2)$ & $2791(3.7)$ & $96(0.4)$ & $1239(4.5)$ \\
\hline Degenerative rheumatic diseases including osteoarthritis & $921(1.2)$ & $14421(19.1)$ & $342(1.2)$ & $4890(17.8)$ \\
\hline Osteoporosis & $111(0.1)$ & 2497 (3.3) & $9(0.0)$ & $186(0.7)$ \\
\hline Chronic pain & $3019(4.0)$ & $21409(28.4)$ & $944(3.4)$ & $6812(24.8)$ \\
\hline Chronic pain* & $227(0.3)$ & $3470(4.6)$ & $93(0.3)$ & $1321(4.8)$ \\
\hline Diseases of the kidney & $57(0.1)$ & $746(1.0)$ & $20(0.1)$ & $262(1.0)$ \\
\hline Gynaecological diseases & $48(0.1)$ & $816(1.1)$ & & \\
\hline \multicolumn{5}{|l|}{ Mental conditions } \\
\hline Dementia & $8(0.0)$ & $132(0.2)$ & $<5(0.0)$ & $55(0.2)$ \\
\hline Substance abuse & $95(0.1)$ & $823(1.1)$ & $54(0.2)$ & $647(2.4)$ \\
\hline Schizophrenia & $6(0.0)$ & $154(0.2)$ & $6(0.0)$ & $60(0.2)$ \\
\hline Depression and anxiety & $792(1.1)$ & $9650(12.8)$ & $189(0.7)$ & $2012(7.3)$ \\
\hline Eating disorders & $34(0.0)$ & $106(0.1)$ & $<5(0.0)$ & $<5(0.0)$ \\
\hline Personality disorders & $72(0.1)$ & $545(0.7)$ & $11(0.00)$ & $129(0.5)$ \\
\hline
\end{tabular}

${ }^{*}$ Chronic pain classification only if no other chronic comorbidities.

(disability pension or death $)^{30}$ — similar to the healthy worker effect. ${ }^{31}$ However, the number of person-years at risk (see online supplementary web appendix 1) shows that a substantial proportion of individuals remain in the working population despite fatal diseases.

2. Conditions with a moderate or small decrease in LTSA in the subsequent years (HR ratio between 0.46 and
0.76 , eg, substance abuse, inflammatory rheumatic disease, osteoarthritis in men and women and thyroid disease in women). Studies examining changes in LTSA of these conditions over time are scarce, but the results are in accordance with two previous studies of inflammatory rheumatic and thyroid diseases ${ }^{17} 18$ suggesting that the risks of LTSA remain elevated over time, but 
Table 4 Adjusted HRs of LTSA of chronic conditions within the first year and subsequent years of diagnosis

\begin{tabular}{|c|c|c|c|c|c|c|c|c|c|c|c|}
\hline \multirow[b]{3}{*}{ Condition } & \multicolumn{5}{|c|}{ Women } & \multirow[b]{3}{*}{ Condition } & \multicolumn{5}{|l|}{ Men } \\
\hline & \multicolumn{2}{|c|}{ First year } & \multicolumn{2}{|c|}{ Subsequent years } & \multirow{2}{*}{$\begin{array}{l}\text { HR } \\
\text { ratio }\end{array}$} & & \multicolumn{2}{|c|}{ First year } & \multicolumn{2}{|c|}{ Subsequent years } & \multirow{2}{*}{$\begin{array}{l}\text { HR } \\
\text { ratio }\end{array}$} \\
\hline & HR & $95 \% \mathrm{Cl}$ & HR & $95 \% \mathrm{Cl}$ & & & HR & $95 \% \mathrm{Cl}$ & HR & $95 \% \mathrm{Cl}$ & \\
\hline Cancer & 7.05 & 6.56 to 7.57 & 1.46 & 1.36 to 1.57 & 0.21 & Cancer & 7.55 & 6.45 to 8.85 & 1.43 & 1.20 to 1.71 & 0.19 \\
\hline Stroke & 4.75 & 4.02 to 5.61 & 1.36 & 1.18 to 1.58 & 0.29 & Schizo & 3.13 & 1.19 to 8.27 & 0.67 & 0.33 to 1.38 & 0.21 \\
\hline ParaHemi & 5.53 & 2.06 to 4.90 & 2.02 & 1.15 to 3.55 & 0.37 & Stroke & 6.14 & 4.93 to 7.66 & 1.44 & 1.16 to 1.78 & 0.23 \\
\hline Kidney & 3.04 & 2.45 to 3.77 & 1.48 & 1.28 to 1.70 & 0.49 & Heart & 4.55 & 4.02 to 5.15 & 1.6 & 1.43 to 1.78 & 0.35 \\
\hline Gynaecol & 2.59 & 2.14 to 3.14 & 1.30 & 1.16 to 1.45 & 0.50 & Haemo & 3.00 & 1.82 to 4.94 & 1.14 & 0.76 to 1.73 & 0.38 \\
\hline Eye & 2.22 & 1.91 to 2.56 & 1.16 & 1.05 to 1.28 & 0.52 & Infec & 0.74 & 0.23 to 2.31 & 1.92 & 1.20 to 3.06 & 0.39 \\
\hline Haemo & 2.05 & 1.56 to 2.70 & 1.17 & 1.02 to 1.35 & 0.57 & Vascular & 3.76 & 2.91 to 4.87 & 1.72 & 1.38 to 2.14 & 0.46 \\
\hline Personality & 3.15 & 2.32 to 4.26 & 1.90 & 1.65 to 2.18 & 0.60 & Arrhythm & 3.07 & 2.44 to 3.86 & 1.56 & 1.31 to 1.85 & 0.51 \\
\hline Vascular & 2.48 & 1.96 to 3.13 & 1.49 & 1.30 to 1.72 & 0.60 & Neuro & 3.00 & 2.50 to 3.60 & 1.67 & 1.48 to 1.88 & 0.56 \\
\hline Abuse & 3.99 & 3.24 to 4.90 & 2.48 & 2.19 to 2.80 & 0.62 & Osteoporosis & 2.82 & 1.81 to 4.40 & 1.58 & 1.21 to 2.07 & 0.56 \\
\hline Arrhythm & 2.10 & 1.79 to 2.47 & 1.31 & 1.19 to 1.45 & 0.62 & Inflarheum & 2.91 & 2.44 to 3.47 & 1.72 & 1.52 to 1.95 & 0.59 \\
\hline Schizo & 2.38 & 1.26 to 4.48 & 1.49 & 1.06 to 2.10 & 0.63 & Eye & 2.30 & 1.80 to 3.15 & 1.38 & 1.17 to 1.62 & 0.60 \\
\hline Heart & 2.60 & 2.29 to 2.95 & 1.67 & 1.53 to 1.83 & 0.64 & Anxdep & 3.45 & 2.97 to 4.00 & 2.17 & 1.98 to 2.38 & 0.63 \\
\hline Neuro & 2.29 & 2.11 to 2.50 & 1.50 & 1.43 to 1.57 & 0.66 & Personality & 2.58 & 1.30 to 5.10 & 1.65 & 1.14 to 2.39 & 0.64 \\
\hline Dementia & 1.87 & 1.00 to 3.47 & 1.23 & 0.83 to 1.83 & 0.66 & Ear & 1.81 & 1.41 to 2.32 & 1.15 & 0.98 to 1.34 & 0.64 \\
\hline Obesity & 2.25 & 2.00 to 2.53 & 1.58 & 1.48 to 1.69 & 0.70 & Dementia & 2.74 & 1.19 to 6.30 & 1.79 & 1.79 to 3.70 & 0.65 \\
\hline Pain* & 2.83 & 2.35 to 3.39 & 2.27 & 2.09 to 2.47 & 0.80 & Liver & 2.33 & 1.44 to 3.78 & 1.82 & 1.37 to 2.41 & 0.78 \\
\hline Pain & 2.90 & 2.75 to 3.06 & 2.36 & 2.30 to 2.42 & 0.81 & Pain* & 3.15 & 2.21 to 4.48 & 2.48 & 2.11 to 2.91 & 0.79 \\
\hline Liver & 1.95 & 1.42 to 2.68 & 1.64 & 1.37 to 1.97 & 0.84 & Thyroid & 1.59 & 0.97 to 2.61 & 1.30 & 0.99 to 1.71 & 0.82 \\
\hline Hyperten & 1.71 & 1.60 to 1.83 & 1.45 & 1.40 to 1.51 & 0.85 & Obesity & 1.83 & 1.31 to 2.56 & 1.87 & 1.47 to 2.37 & 1.02 \\
\hline Pulmonary & 1.69 & 1.53 to 1.87 & 1.55 & 1.49 to 1.61 & 0.92 & Diabetes & 1.57 & 1.24 to 1.98 & 1.82 & 1.60 to 2.06 & 1.16 \\
\hline Diabetes & 1.60 & 1.35 to 1.91 & 1.49 & 1.36 to 1.63 & 0.93 & & & & & & \\
\hline Skin & 1.40 & 1.27 to 1.54 & 1.33 & 1.28 to 1.38 & 0.95 & & & & & & \\
\hline
\end{tabular}

Significant HR in bold $(\mathrm{p}<0.05)$; HR adjusted for immigrant status, highest attained education, marital status, calendar years and job-type; $\mathrm{HR}$ ratio of the subsequent years of diagnosis was divided with the first year: extreme decrease (HR ratio $\leq 0.25$ ); strong decrease $(>0.25$ hour ratio $\leq 0.40$ ); moderate decrease $(>0.40$ hour ratio $\leq 0.67$ ); small decrease $(>0.67$ hour ratio $\leq 0.91)$; no change or increase $(>0.91$ hour ratio >1.00); HR ratio not valid: no marked colour.

${ }^{*}$ Chronic pain classification only if no other chronic comorbidities.

Anxdep, depression and anxiety; Arrhythm, caridiac arrhythmia and valve disease; Endo, other endocrine diseases and malnutrition; Gynaecol, gynaecological diseases; Haemo, benign haematologic diseases including anaemia; Hyperten, hypertension; Infec, chronic infection; Inflarheum, inflammatory rheumatic disease; LTSA, long-term sickness absence; Neuro, neurological diseases; Osteoarthr, degenerative rheumatic diseases and osteoarthritis; ParaHemi, paraplegia and hemiplegia; Schizo, schizophrenia.

some improvement in work capacity may be expected after the first year of diagnosis.

3. Conditions with little or no change in elevated risks of LTSA (HR ratio between 0.92 and 0.95: chronic pulmonary disease, diabetes and skin disease in women) or increase in risks throughout the study period (HR ratio between 1.02 and 1.16 obesity and diabetes in men). Although previous literature documents that obesity is associated with LTSA, ${ }^{32}$ only one study examined changes in LTSA over time in diabetes. In accordance 
with results of the present study, the study showed that the length of sickness absence spells due to diabetes increased over time. ${ }^{33}$ Future research should further examine whether these types of chronic conditions may be more prevalent in the work force than acute life-threatening conditions, because these chronic conditions are characterised by a slow progression.

Some of the chronic conditions had no significantly elevated risks of LTSA (chronic infection, dementia, schizophrenia, eating disorders), which presumably reflect lack of statistical power because of few cases (table 1).

Our results showed pivotal gender differences: many conditions showed stronger association with LTSA for men than for women. Previous studies have indicated that women have more short-term sickness absence than men, ${ }^{10} 34$ but not necessarily more LTSA. ${ }^{12}{ }^{13}$ The higher risks of LTSA for men may reflect the overall gender differences in health status and health behaviour: men have a higher risk of fatal conditions at an earlier age, for example, cardiovascular conditions ${ }^{35}$ and are less likely to seek help in the early stages of a condition, which can result in worse outcomes. ${ }^{36} 37$

We estimated HR by comparing the risk of LTSA in those with a particular condition with those without the condition without excluding participants with other comorbidities. Thus, the increased risk of LTSA seen in for example, individuals with hypertension may partly reflect the impact of comorbidities on hypertension. We did not attempt to evaluate the combined effect of multimorbidity in this study, since such multimorbidity may involve complex interaction effects that would be difficult to model for all the diseases. However, we evaluated the impact of chronic pain in two different ways: by either including or excluding individuals with other comorbidities. The different approaches showed little difference between HR estimates and showed that the analyses that included comorbidities had higher statistical power.

Major strengths of the study were the study of a large cohort of $>100000$ individuals in a prospective design with up to 17 years of follow-up. However, selection bias could threaten the internal validity as we had to exclude a large proportion of individuals because data were missing on key variables (16\% of entire study population). Additionally, our cohort was drawn from the general population but oversampled women and older age groups. We find it unlikely that this caused measurement errors because age was the underlying time variable in the analyses and results for men and women were analysed separately. However, assumptions about the prevalence of the conditions cannot reliably be drawn from the present results.

Among other strengths were the validity of diagnosis and the availability of data from both the primary and secondary healthcare sector and the inclusion of a wide range of time-depending confounding variables. Misclassification of LTSA was unlikely as it was connected to the reimbursement from the government, but participants with a chronic disease that did not require hospitalisation or treatment with disease-specific prescribed medication could have been misclassified. Although the number of people living of a fortune without collecting social benefits may be small, ${ }^{29}$ they could have been misclassified as working in our study.

A full description of the social consequences of chronic disease includes disability pension and unemployment. However, dealing with these outcomes in addition to LTSA would have introduced too much complexity when comparing 32 chronic diseases. The Danish labour market can be characterised as a 'flexi-curity' system with a high transition between employment and unemployment, but a welfare system with easy access to social benefits. ${ }^{38}$ The risk of LTSA may differ according to different labour market systems of different countries and may limit the external validity to countries with a comparable degree of social security as the present study.

\section{CONCLUSION}

This study identified three different patterns of LTSA associated with the courses of 32 different chronic conditions prevalent in the work force: (1) a strong decrease of LTSA from the first to subsequent years (eg, stroke and cancer), (2) a moderate or small decrease in LTSA from the first to subsequent years (eg, substance abuse, inflammatory rheumatic disease and thyroid disease in women), (3) conditions with no change in elevated risks of LTSA (chronic pulmonary disease, diabetes and skin disease in women) or increase in risks over time (obesity and diabetes in men). The result can help tailor strategies to manage the work disability associated with different chronic diseases over time. In addition to gender differences and disease duration, future studies should consider the influence of treatment adherence and co-existence of other diseases on work disability.

\section{Author affiliations \\ ${ }^{1}$ Steno Diabetes Center Copenhagen, Health promotion, Gentofte, Denmark ${ }^{2}$ Department of Epidemiology, The National Research Center of the Working Environment, Copenhagen, Denmark \\ ${ }^{3}$ Department of Analyses, The Danish Working Environment Authority, Copenhagen, Denmark \\ ${ }^{4}$ COPECARE Center for Rheumatology and Spine Diseases, Centre of Head and Orthopaedics, Copenhagen University Hospital (Rigshospitalet), Glostrup, Denmark ${ }^{5}$ Department of Clinical Medicine, Faculty of Health and Medical Sciences, University of Copenhagen, Copenhagen, Denmark \\ ${ }^{6}$ Department of Medical Endocrinology, Copenhagen University Hospital Rigshospitalet, Copenhagen, Denmark \\ ${ }^{7}$ Social conditions, Statistics Denmark, Copenhagen, Denmark \\ ${ }^{8}$ Optum Patient Insight, Johnston, Rhode Island, USA}

Contributors JBB was responsible for the original idea, which was codeveloped by all authors. All authors (MAN, KC, JP, TW, SMH, MLH, JBB) developed the criteria for the chronic disease framework prevalent in the work force, by reviewing all ICD-10 diagnoses and identifying corresponding prescribed medicine and their Anatomical Therapeutic Chemical (ATC) and validation via statistical analyses. Additionally, three medical doctors (JBB, TW, MLH) validated the diagnoses identified via prescribed medicine (ATC codes) and JP carried out all the data-management and statistical analyses, which was supervised by JBB. MAN was responsible for writing the manuscript, which was critically revised by all coauthors.

Funding The authors have not declared a specific grant for this research from any funding agency in the public, commercial or not-for-profit sectors. 
Competing interests None declared.

Patient consent Not required.

Provenance and peer review Not commissioned; externally peer reviewed.

Data sharing statement The data sets generated and/or analysed during the current study cannot be made publicly available according to the Danish law of personal data protection, allowing only the person responsible for the data management to manage data after approval from the Danish Protection Agency. However,data inquires or further suggestions for analyses can be made to the corresponding author or Jakob B. Bjorner.

Open access This is an open access article distributed in accordance with the Creative Commons Attribution Non Commercial (CC BY-NC 4.0) license, which permits others to distribute, remix, adapt, build upon this work non-commercially, and license their derivative works on different terms, provided the original work is properly cited and the use is non-commercial. See: http://creativecommons.org/ licenses/by-nc/4.0/

(c) Article author(s) (or their employer(s) unless otherwise stated in the text of the article) 2018. All rights reserved. No commercial use is permitted unless otherwise expressly granted.

\section{REFERENCES}

1. Murray CJ, Vos T, Lozano R, et al. Disability-adjusted life years (DALYs) for 291 diseases and injuries in 21 regions, 1990-2010: a systematic analysis for the Global Burden of Disease Study 2010. Lancet 2012;380:2197-223.

2. Organization WH. Global Health Risks: Mortality and Burden of disease attributable to selected major risks. Geneva, Switzerland: WHO Press, 2009.

3. Alliance CD. The chronic disease alliance: $A$ unified prevention approach. 2010. Chronic Disease Alliance http://Press release CDA FINAL_2_.pdf

4. Bodenheimer T, Chen E, Bennett HD. Confronting the growing burden of chronic disease: can the U.S. health Care workforce do the job? Health Aff 2009;28:64-74.

5. Sorensen G, Landsbergis $\mathrm{P}$, Hammer L, et al. Preventing chronic disease in the workplace: a workshop report and recommendations. Am J Public Health 2011;101 Suppl 1(Suppl 1):S196-207.

6. OECD. Pensions at a glance 2009: Retirement income systems in OECD countries, 2006.

7. OECD. Pensions at a glance: OECD and G20 indicators. Paris, 2013.

8. Rijken M, Spreeuwenberg P, Schippers J, et al. The importance of illness duration, age at diagnosis and the year of diagnosis for labour participation chances of people with chronic illness: results of a nationwide panel-study in The Netherlands. BMC Public Health 2013;13:803.

9. Andrea H, Beurskens AJ, Metsemakers JF, et al. Health problems and psychosocial work environment as predictors of long term sickness absence in employees who visited the occupational physician and/or general practitioner in relation to work: a prospective study. Occup Environ Med 2003;60:295-300.

10. Bergh H, Baigi A, Månsson J, et al. Predictive factors for longterm sick leave and disability pension among frequent and normal attenders in primary health care over 5 years. Public Health 2007:121:25-33.

11. Coutu M, Cote D, Baril R. The Work-Disabled Patient. In: Loisel P, Anema JR, eds. Handbook of Work Disability: Prevention and Management. New York: Springer, 2013:15-31.

12. Kivimäki M, Head J, Ferrie JE, et al. Sickness absence as a global measure of health: evidence from mortality in the Whitehall II prospective cohort study. BMJ 2003;327:364.

13. Ármannsdóttir B, Mårdby AC, Haukenes I, et al. Cumulative incidence of sickness absence and disease burden among the newly sick-listed, a cross-sectional population-based study. BMC Public Health 2013;13:329.

14. Casimirri E, Vaccari A, Schito M, et al. Chronic diseases are strongly associated with sickness absences in a sample of Italian public employees. Int J Occup Med Environ Health 2014;27:343-54.
15. Collins JJ, Baase CM, Sharda CE, et al. The assessment of chronic health conditions on work performance, absence, and total economic impact for employers. J Occup Environ Med 2005;47:547-57.

16. Goetzel RZ, Hawkins K, Ozminkowski RJ, et al. The health and productivity cost burden of the "top 10" physical and mental health conditions affecting six large U.S. employers in 1999. J Occup Environ Med 2003:45:5-14.

17. Hansen SM, Hetland ML, Pedersen J, et al. Effect of Rheumatoid Arthritis on Longterm Sickness Absence in 1994-2011: A Danish Cohort Study. J Rheumatol 2016;43:707-15.

18. Nexo MA, Watt T, Pedersen J, et al. Increased risk of long-term sickness absence, lower rate of return to work, and higher risk of unemployment and disability pensioning for thyroid patients: a Danish register-based cohort study. J Clin Endocrinol Metab 2014;99:3184-92.

19. Thygesen LC, Daasnes C, Thaulow I, et al. Introduction to Danish (nationwide) registers on health and social issues: structure, access, legislation, and archiving. Scand J Public Health 2011;39(7 Suppl):12-16.

20. Organization WH. International Classification of Diseases Geneva. Switzerland: WHO Press, 2010

21. Nolte S, McKee M. Caring for people with chronic conditions: $A$ health system perspective. Berkshire, UK: Open University Press, 2008.

22. Turner JA, Franklin G, Fulton-Kehoe D, et al. ISSLS prize winner: early predictors of chronic work disability: a prospective, population-based study of workers with back injuries. Spine 2008;33:2809-18

23. Lynge E, Sandegaard JL, Rebolj M. The Danish National Patient Register. Scand J Public Health 2011;39(7 Suppl):30-3.

24. Mors O, Perto GP, Mortensen PB. The Danish Psychiatric Central Research Register. Scand J Public Health 2011;39(7 Suppl):54-7.

25. Kildemoes HW, Sørensen HT, Hallas J. The Danish National Prescription Registry. Scand J Public Health 2011;39(7 Suppl):38-41.

26. Hjollund NH, Larsen FB, Andersen JH. Register-based follow-up of social benefits and other transfer payments: accuracy and degree of completeness in a Danish interdepartmental administrative database compared with a population-based survey. Scand J Public Health 2007;35:497-502.

27. Stender P, Leth-Sørensen S. Register-based statistics on the Danish Labour market-new possibilities in relation to external user needs: Statistics Denmark, 2008.

28. Timmermans B. The Danish Integrated Database for Labour Market Research: Towards demystification of the English speaking audienc. The Danish research unit for industrial dynamics: University of AAlborg, 2010. http://vbn.aau.dk/en/publications/the-danishintegrated-database-for-labor-market-research $(15 \mathrm{~b} 64 \mathrm{ec} 0-41 \mathrm{cb}-$ 11df-a11e-000ea68e967b)/export.html.

29. Pedersen J, Bjorner JB, Burr H, et al. Transitions between sickness absence, work, unemployment, and disability in Denmark 20042008. Scand J Work Environ Health 2012;38:516-26.

30. Vahtera J, Pentti J, Kivimäki M. Sickness absence as a predictor of mortality among male and female employees. J Epidemiol Community Health 2004;58:321-6.

31. Li CY, Sung FC. A review of the healthy worker effect in occupational epidemiology. Occup Med 1999;49:225-9.

32. Ferrie JE, Head J, Shipley MJ, et al. BMI, obesity, and sickness absence in the Whitehall II study. Obesity 2007;15:1554-64.

33. Dray-Spira R, Herquelot E, Bonenfant S, et al. Impact of diabetes mellitus onset on sickness absence from work-a 15-year follow-up of the GAZEL Occupational Cohort Study. Diabet Med 2013;30:549-56.

34. Bekker MH, Rutte CG, van Rijswijk K. Sickness absence: A genderfocused review. Psychol Health Med 2009;14:405-18.

35. Oksuzyan A, Crimmins E, Saito Y, et al. Cross-national comparison of sex differences in health and mortality in Denmark, Japan and the US. Eur J Epidemiol 2010;25:471-80.

36. Galdas PM, Cheater F, Marshall P. Men and health help-seeking behaviour: literature review. J Adv Nurs 2005;49:616-23.

37. Oksuzyan A, Juel K, Vaupel JW, et al. Men: good health and high mortality. Sex differences in health and aging. Aging Clin Exp Res 2008;20:91-102.

38. Andersen TM, Svarer M. Flexicurity-Labour Market Performance in Denmark. CESifo Econom Stud 2007;53:389. 